\title{
Objects Counting on Mobile Platform in Dusty Environment Through Load Measurement
}

\author{
Moiz Chasmai ${ }^{1}$, Ansari $\mathrm{AN}^{1}$, Arun Barde ${ }^{1}$, Ganesh Mutkule ${ }^{1}$ \\ ${ }^{1}$ (Research \& Development Establishment (Engineers), DRDO, Pune, India)
}

\begin{abstract}
In applications where the electronic systems are required to be used in mobile and dusty environmental conditions, the performance of systems becomes critical with respect to selection of sensors as they need to be done carefully. In such harsh conditions the main objective and challenge is to select suitable sensors and mount the sensors such that high degree of accuracy and reliability is achieved. Our application required to count the number of objects at any instant on a transverse platform mounted on a vehicle that encounters dusty environmental conditions. In our application, we have used load cells with proper mounting to address the specific end use conditions. In this paper we have discussed the selection of sensor, mounting design, related electronic circuitry and its testing. The tests were conducted to count the number of objects on transverse platform through the load measurement. The results show that the design is robust and can work in a dusty and mobile environment with high accuracy.
\end{abstract}

Keywords: Load cell, Sensors, Strain gauge, Transverse platform

\section{Introduction}

There was a requirement to count the number of objects on the transverse platform mounted on the vehicle while it is moving. The vehicle has to move in harsh conditions in the dusty environment. As shown in Fig. 1, the objects are placed in a palletized container that can carry up to 169 objects. This container is mounted on the vehicle. Objects are of the dimensions 1200x110x97 mm with a weight of $10 \mathrm{~kg}$ each. Each movable pallet holds 13 such objects and the container has 13 such palates. The pallets have a mechanism to be moved vertically. At a time, one pallet containing 13 objects is lowered until all the 13 objects are loaded onto the transverse platform. An automatic mechanism was required to be made that not only senses the presence of objects but also gives the number of objects present on the platform at any instant as the objects are removed from the transverse platform one by one.

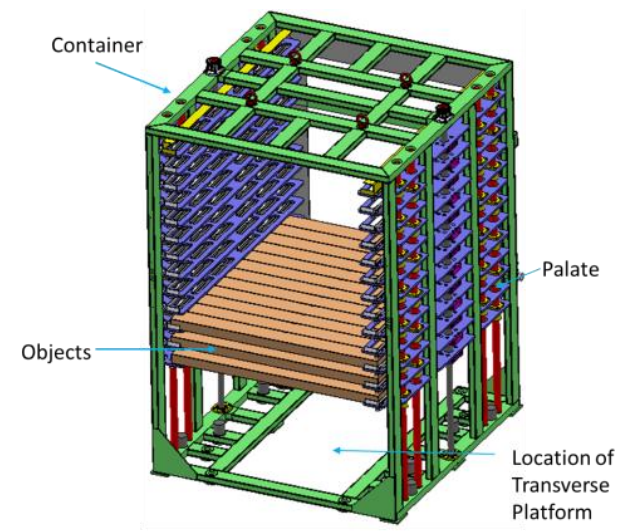

Figure 1: Container model

Various types of COTS sensors are available in the market that can be used to sense the presence of the objects on the transverse platform and to arrive at the number of objects present at any given instant. The sensors namely visible light sensors, laser sensor, infrared, ultrasonic sensors could have been used for this purpose. But these sensors would not work in such harsh and dusty conditions where the visibility is low. Limit switches and inductive proxy switches could not be used because of mounting space constraints and as separate mounting and cabling will be required to mount these sensors, with one sensor for each object. Because of such constraints, these options were ruled out.

As the direct method of counting the objects in such application could not work using the above mentioned sensors, we resorted to the indirect method of counting the objects by measuring the load on the transverse platform. Taking into consideration the space constrains and environmental conditions, we selected load cell for this application. Load cell is a transducer that converts mechanical force into electrical signal. 
There are various types of load cells based on measuring principle like strain gauge, bending, shear, compression and ring torsion [1]. Load cell construction and load transmission mounting depends on the measurement principle used. [2] Based on our requirement we have selected strain gauge type load cell. Strain gauge based load cells use Wheatstone bridge configuration in which four arms of the bridge makes a balanced circuit as shown in Fig. 2. In each arm of load cell one spring element is used, which converts the applied force or mass to a measurable Strain. For good quality load cells spring material is made up from 4340 alloy steel, 17-4 PH stainless steel and 2024 T351 and 2024 T3 aluminium. [3] When the load is applied to this balanced circuit, the arm is deformed and as a result the Ohmic resistance of these arms change which unbalances the bridge. The amount of unbalance in the circuit is equivalent to the applied load. Temperature compensation is also used in the load cells by making all the parts out of the same material, so that their relative temperature effects are equal, causing them to cancel each other out. [4] For each load cell, at least 4 strain gauges are connected together to form a complete Wheatstone bridge. The stretched or compressed strain gauges are connected so that the resistance changes are added together to form a total imbalance in the bridge. Across one diagonal, the power supply is applied and on the other diagonal, the voltage output is measured. For a given excitation voltage $\mathrm{V}$, the output of the load cell is few $\mathrm{mV} / \mathrm{V}$. Instrumentation amplifiers are used to amplify this signal and signal level is raised to a significant level after which it can be further processed.

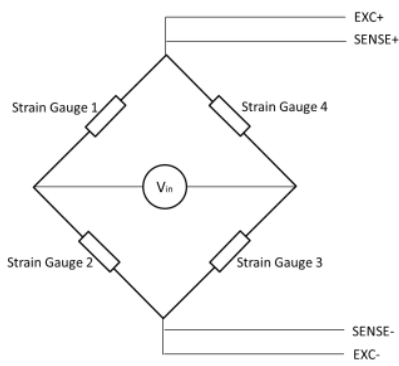

Figure 2: Wheatstone Bridge

A mechanical system was then designed and manufactured. Four load cells were mounted on the mechanical assembly to measure the load of the bar type objects present on the mobile transverse platform. Tests were carried out to measure the presence of the objects as well as count the number of objects on the transverse platform using this mechanism in dusty and mobile conditions. The system was able to measure the load on the transverse platform. This load was further calibrated in to the number of objects. The results obtained with this method were satisfactory. It was verified that the system based on load cell sensing mechanism is not affected by dusty conditions. It was also verified that the counting accuracy was not affected by vibrations produced due to vehicle engine and by cross country movement of the vehicle.

\section{Sensor Selection}

There are certain features like accuracy, environmental conditions, range of measurement, resolution, repeatability and cost, which have been considered when we choose a sensor [5]. As the requirement was to measure the presence of the objects on the transverse platform and count the number of objects on it, there were many options available. Following options were evaluated.

An array of 13 Infrared sensors was placed in front of each object's location on the transverse platform to mark the presence or absence of the respective objects coming in front of the sensors. It was observed that these sensors were not able to give the reliable output in dusty environment. None of the optical sensors work in such conditions. Another option was to use the proximity sensors, i.e., inductive or capacitive proxy sensors. Inductive proxy would not work here as the objects are of plastic material. Capacitive proxy sensors could have been used, but this requires an array of 13 sensors, one for each object. Due to large number of channels required and space constraints for mounting and cabling, these sensors were ruled out. After analysing all the options, it was decided to select strain gauge based load cells as dusty conditions has no effect on its functioning and the requirement can be fulfilled with minimum number of sensors.

The load cells are selected based on the mode of operation, number of load cells required, capacity, performance or accuracy level related to system requirements, method of mounting, environmental requirements, sealing level (ingress protection) and material of construction and its cost. In our application, a precise measurement of the load was not required. The load to be experienced by the load cells was from the top only. So it was supposed to experience compressive load. Based on the shape, loading mechanism and direction of loading on the load cell, it can be further divided into single point, button, S type, pan cake, shearbeam, donut, and canister type of load cells for various applications. Taking into consideration the requirement, button type load cell suits our application. A low accuracy load cells can also give satisfactory results. Here, we have selected load cell with an accuracy of $0.01 \%$. 
The capacity of the load cell to measure the load should be selected based on the total load of the objects to be placed on the transverse platform. While selecting the load cell, we have to see that the maximum dynamic range of the sensor is utilized. At the same time, due to uneven distribution of the load, none of the sensors should go into saturation.

\section{System Design And Development}

There was a requirement to design the system on $8 \times 8$ transmission vehicle with frame dimensions of $6.5 \times 2.55 \mathrm{~m}^{2}$. A palletized container as shown in Fig. 3 was manufactured and mounted onto the frame of the vehicle. Objects were required to be shifted one at a time to the longitudinal conveyor belt that further takes the object to the chute, which lays the object on the ground.
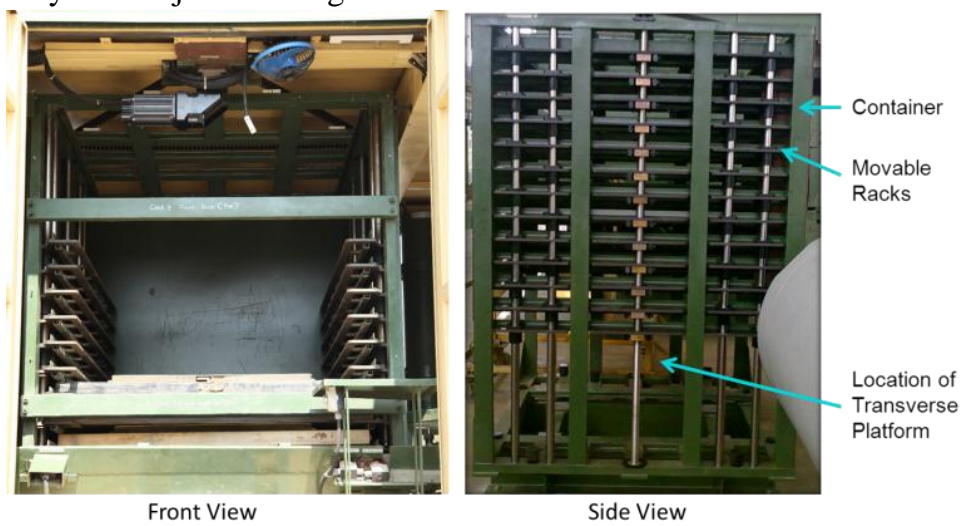

Figure 3. Container

A transverse platform as shown in the Fig. 4 was designed and manufactured on which objects rests and are shifted one by one onto the longitudinal conveyor belt with the help of pushing mechanism. This transverse platform is independent entity that is mounted below the container. The transverse platform has to carry the load of 13 objects i.e. $(13 * 10)=130 \mathrm{~kg}$. Due to mechanical constraints, there was not enough space to mount a single plate platform. The transverse platform was made with two separate vertical beams kept at a distance of 0.7 meter. Optimally, four load cells were required to be used to provide support and equal distribution of load on the loading plates. Two load cells are installed at corners of each vertical beam. These load cells have threaded tip fitted on them. A small circular plate of $5 \mathrm{~mm}$ thickness is fastened onto this threaded tip. Rigid plates of the length of the transverse platform are fixed onto the two load cells circular plates of each beam on which the objects rest. The loading plates are mounted such that they are in contact only with the load cells circular plates. This will enable to transfer the total load of the objects on the load cells only without distributing the load to any other part of the transverse platform. The actual mounting of the load cells is shown in Fig. 5. The objects from the transverse platform are pushed to the longitudinal conveyor one by one with the help of the pusher mechanism.

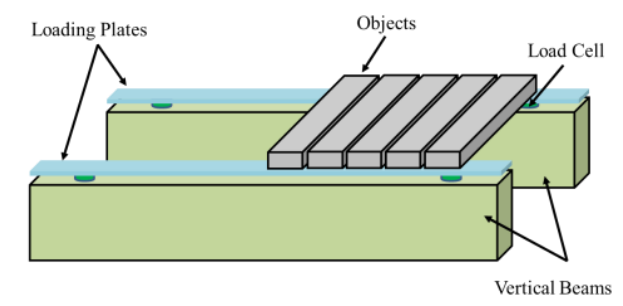

Figure 4: Transverse Platform with loading plates

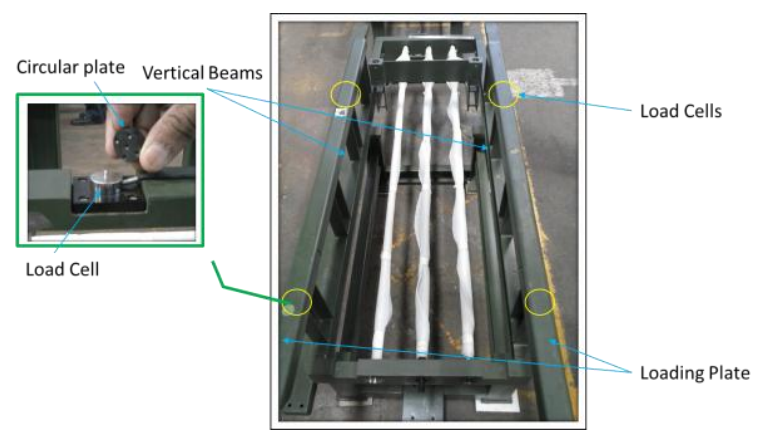

Figure 5: Load cells mounting platform 
Each load cell gives an output in the range of $0-7.5 \mathrm{mV}$. As the output of the load cells is weak, each load cell output was fed to different instrumentation amplifiers that will amplify the signal to a desirable level. Instrumentation amplifier because it has very high CMRR, high input impedance, low output impedance and very low offset voltages, which has nearly ideal parameters to be used for amplification of weak signals. We have used Analog Devices (AD624) [6] instrumentation amplifier (IA) with Gain 100. The output of each amplifier was in the range of $0-0.75 \mathrm{~V}$. To reduce the number of channels at the receiving end, all the four amplified load cells output are added using OP-AMP (OP07) [7] based adder with an amplification factor of 1.66. This gives an output of $0-5 \mathrm{~V}$. When the signal is transmitted in the form of voltage, there is a drop along the length of the cable because of its resistance, which may lead to false reading. Here, as this signal has to travel a longer distance before it is logged and processed further, it was desirable to convert this voltage signal into a current signal. Hence, a voltage to current convertor (1B22) [8] was used to convert the signal into current. This current signal is calibrated to give the output on the scale of 4-20 mA as shown in Fig. 6.

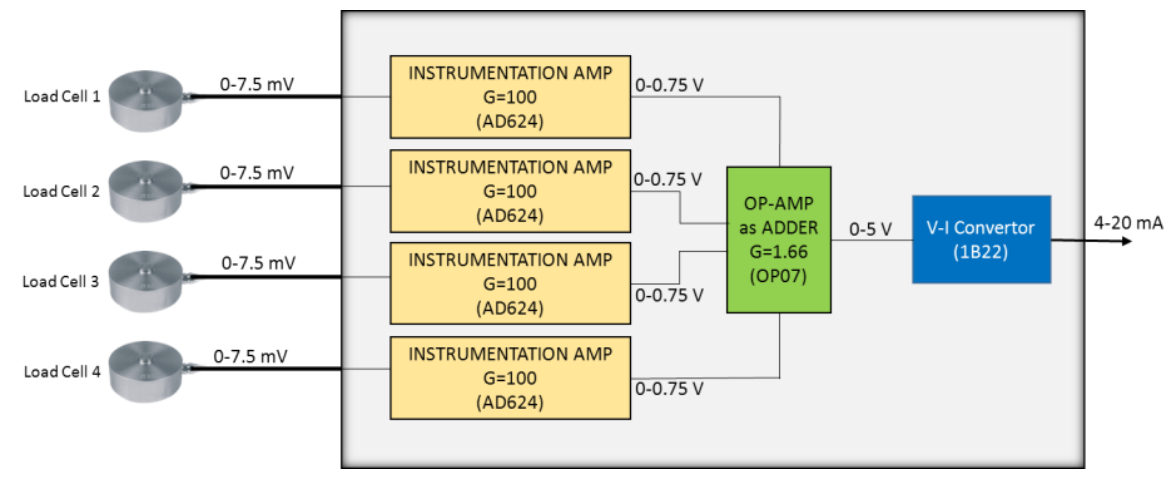

Figure 6: Block diagram of Signal Conditioning Module

\section{Results And Discussions}

Initially, based on the specifications of the load cells, we have calculated the theoretical values of the corresponding voltage output and the current values with respect to the load to be applied on the load cells for our application. The theoretical calculations are discussed below.

Load Cell Excitation Voltage $\mathrm{V}_{\text {exe }}=5 \mathrm{~V}$

Rated Output $\mathrm{V}_{\mathrm{o}}=1.5 \mathrm{mV} / \mathrm{V}$

Load Cell Capacity $=50 \mathrm{~kg}$

No. of Load cells on Transverse platform $=04$

Total Capacity $=200 \mathrm{~kg}$

As the rated output of a load cell is $\mathrm{V}_{0}=1.5 \mathrm{mV} / \mathrm{V}$ and excitation voltage given to the load cell is $\mathrm{V}_{\text {exe }}=5 \mathrm{~V}$, each load cell can give a maximum output of $\mathrm{V}_{\max }=7.5 \mathrm{mV}$ at full load.

Total range of the load cells is 0 to $200 \mathrm{~kg}$. For this range of load, combined output of load cells will range from 0 to $30 \mathrm{mV}$. Considering a linear relationship between load and $\mathrm{mV}$ output, it gives an equation given below:

where $\mathrm{X}=$ load in $\mathrm{kg}$ and $\mathrm{Y}=$ load cell output in $\mathrm{mV}$.

$$
\mathrm{Y}=0.15^{*} \mathrm{X}
$$

This voltage output ( 0 to $30 \mathrm{mV}$ ) is further converted into current (4 to $20 \mathrm{~mA}$ ) as given in equation below:

$$
\mathrm{Z}=(0.53333 * \mathrm{Y})+4
$$

where $\mathrm{Y}=$ load cell output in $\mathrm{mV}$ and $\mathrm{Z}=$ equivalent current in $\mathrm{mA}$.

Based on the above two equations, the load is converted into voltage and then current as given in Table 1 (Theoretical).

Here, as the maximum load that is applied on the transverse platform is $130 \mathrm{~kg}$ only, the voltage range is $0-$ $19.5 \mathrm{mV}$ and the current range is $4-14.399 \mathrm{~mA}$.

Two loading plates are kept on the load cells, which has a dead weight of $4 \mathrm{~kg}$ each. This amounts to $0.6 \mathrm{mV}$, which is an offset to the load measurement. This offset is incorporated into the calculations to give the exact load of objects.

Once the setup was made, all the 13 objects were placed on the transverse platform and the load was measured while keeping the vehicle stationary. The measurements are not taken during the pushing operation of the objects, as it may lead to ambiguous reading because of the pushing force applied by the mechanism on the objects while pushing. The objects were removed one by one from the transverse platform and the corresponding readings were taken as given in Table 1 (Static condition). Similar test was carried out on a moving vehicle to find out the effect of vehicle vibrations and cross country movement of the vehicle. The readings are given in Table 1 (Dynamic condition). For the static and dynamic conditions, based on the current 
and voltage output of the circuit measured manually, the load and number of objects were computed as given in Table 1.

Table 1. Load Measurement Data

\begin{tabular}{|r|r|r|r|r|r|r|r|r|r|r|r|}
\hline \multicolumn{4}{|c|}{ Theoretical } & \multicolumn{4}{|c|}{ Static Condition } & \multicolumn{3}{|c|}{ Dynamic Condition } \\
\hline $\begin{array}{r}\text { No. of } \\
\text { Objects }\end{array}$ & $\begin{array}{c}\text { Load } \\
(\mathrm{kg})\end{array}$ & $\begin{array}{c}\text { Volt } \\
(\mathrm{mV})\end{array}$ & $\begin{array}{c}\text { Current } \\
(\mathrm{mA})\end{array}$ & $\begin{array}{c}\text { No. of } \\
\text { Objects }\end{array}$ & $\begin{array}{c}\text { Load } \\
(\mathrm{kg})\end{array}$ & $\begin{array}{c}\text { Volt } \\
(\mathrm{mV})\end{array}$ & $\begin{array}{c}\text { Current } \\
(\mathrm{mA})\end{array}$ & $\begin{array}{c}\text { No. of } \\
\text { Objects }\end{array}$ & $\begin{array}{c}\text { Load } \\
(\mathrm{kg})\end{array}$ & $\begin{array}{c}\text { Volt } \\
(\mathrm{mV})\end{array}$ & $\begin{array}{c}\text { Current } \\
(\mathrm{mA})\end{array}$ \\
\hline 0 & 0 & 0 & 4 & 0 & 0.11 & 0.0165 & 4.0088 & 0 & 0.19 & 0.0285 & 4.0152 \\
\hline 13 & 130 & 19.5 & 14.399 & 13 & 130.88 & 19.632 & 14.470 & 13 & 131.72 & 19.758 & 14.537 \\
\hline 12 & 120 & 18 & 13.599 & 12 & 119.52 & 17.928 & 13.561 & 12 & 118.32 & 17.748 & 13.465 \\
\hline 11 & 110 & 16.5 & 12.799 & 11 & 110.79 & 16.618 & 12.863 & 11 & 109.03 & 16.354 & 12.722 \\
\hline 10 & 100 & 15 & 12 & 10 & 100.32 & 15.048 & 12.025 & 10 & 101.02 & 15.153 & 12.081 \\
\hline 9 & 90 & 13.5 & 11.2 & 9 & 89.41 & 13.411 & 11.152 & 9 & 90.97 & 13.645 & 11.277 \\
\hline 8 & 80 & 12 & 10.4 & 8 & 79.56 & 11.934 & 10.364 & 8 & 81.59 & 12.238 & 10.527 \\
\hline 7 & 70 & 10.5 & 9.5999 & 7 & 69.23 & 10.384 & 9.5383 & 7 & 68.61 & 10.291 & 9.4887 \\
\hline 6 & 60 & 9 & 8.7999 & 6 & 59.61 & 8.9415 & 8.7687 & 6 & 61.58 & 9.237 & 8.9263 \\
\hline 5 & 50 & 7.5 & 7.9999 & 5 & 49.72 & 7.458 & 7.9775 & 5 & 48.23 & 7.2345 & 7.8583 \\
\hline 4 & 40 & 6 & 7.1999 & 4 & 39.55 & 5.9325 & 7.1639 & 4 & 41.36 & 6.204 & 7.3087 \\
\hline 3 & 30 & 4.5 & 6.3999 & 3 & 30.42 & 4.563 & 6.4335 & 3 & 31.53 & 4.7295 & 6.5223 \\
\hline 2 & 20 & 3 & 5.5999 & 2 & 20.37 & 3.0555 & 5.6295 & 2 & 20.85 & 3.1275 & 5.6679 \\
\hline 1 & 10 & 1.5 & 4.8 & 1 & 10.13 & 1.5195 & 4.8103 & 1 & 9.67 & 1.4505 & 4.7735 \\
\hline 0 & 0 & 0 & 4 & 0 & 0.13 & 0.0195 & 4.0104 & 0 & 0.2 & 0.03 & 4.016 \\
\hline
\end{tabular}

The graph shown in Fig. 7 compares the load measured theoretically and practically while keeping the vehicle stationary. Experimental study in this condition gave an RMS error of $4.94 \%$ with respect to weight of one object and 0\% error for counting the objects. The graph shown in Fig. 8 compares the load measured theoretically and practically while the vehicle is moving. Experimental study in this dynamic condition gave an RMS error of $12.62 \%$ with respect to weight of one object and $0 \%$ error for counting the objects. This increase in error is because of the errors introduced by the vehicle vibrations and vehicle movement. In both the cases, the error should not exceed the weight of a single object, i.e., $\geq 50 \%$ with respect to weight of one object, as it may lead to false indication of number of objects present on the transverse platform. If the error crosses $50 \%$ of the weight of one object, it will lead to incorrect calculation of number of objects. However, load cell based system accuracy depends considerably on the application of use, physical load introduction to the transducer and distributing factors [9].

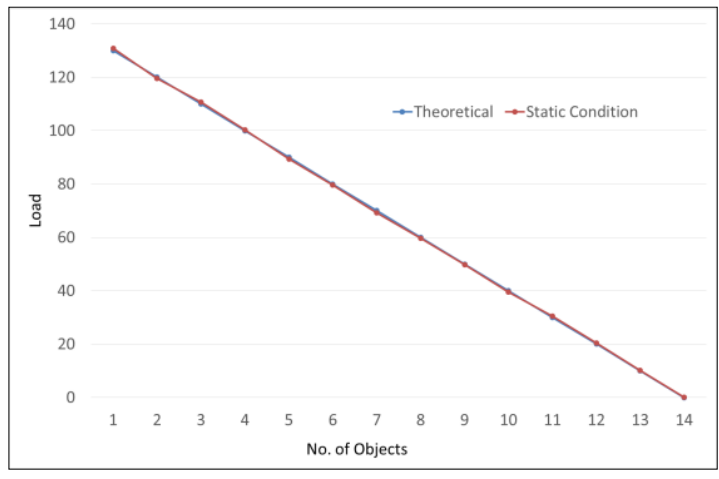

Figure 7. Plot for Static Condition

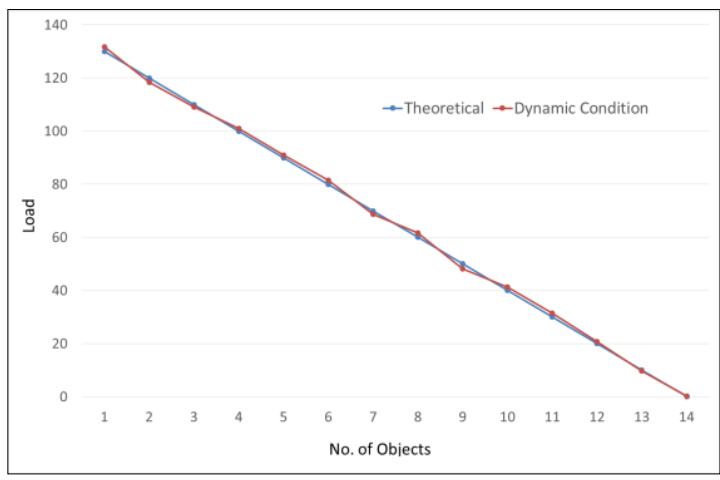

Figure 8. Plot for Dynamic Condition

\section{Conclusions}

In dusty and unfavourable environmental conditions, load cells give a better option for object counting using load measurement where space constraint is an important factor. The load cell can be selected based on the type, weight of individual object, number of objects to be counted and principle of measurement. However, proper mounting and signal conditioning of the load cell output needs to be taken care during design for efficient system performance. This arrangement is best suited where the total error due to vehicle vibrations and movements is less than half of the single object's weight. In other words, this system is limited to be used in cases where the quantum change in the weight by addition or removal of one object is more than double the total system error. 


\section{Acknowledgement}

The authors are grateful to Dr. S Guruprasad, Director, R\&DE (E), Pune for allowing us to publish this work. We express our sincere thanks and appreciation to Mr. VV Parlikar for their constant encouragement and guidance. We are also thankful to Mr. Jagat Prakash Singh for scientific discussions.

\section{References}

[1] VPG transducers, Doc No 11866, Rev 21 Feb 2012, pg. no. 1,2

[2] Guide for load cells, Welmec 2.4, issue 2, Aug 2001, pg. no. 9, 10

[3] HAR RY E. LOCK ERYMEE, What Puts the 'Quality' Into High Quality Strain Gage Load Cells?, White paper

[4] Load Cells: A Primer on the Design and Use of Strain Gage Force Sensors, pg no 11

[5] Introduction to type of sensors, ilabs, www.ilabsindia.com, pg 1-10

[6] http://www.analog.com/static/imported-files/data sheets/AD624.pdf

[7] http://www.analog.com/static/imported-files/data_sheets/OP07.pdf

[8] http://www.analog.com/static/imported-files/data_sheets/1B22.pdf

[9] Load cell accuracy in relation to the conditions of use, VPG transducers, Application note VPG-02, Doc No 11864, rev 29 Nov 2011, pg. no. 1-7 